\title{
A microclimate regulation study of Ficus altissima under winter conditions in lower subtropical China
}

\author{
Wan Deng \\ Chunhua Xia ( $\square$ ciosptde@163.com ) \\ Jingyu Chen \\ Yanji Jiang
}

\section{Research Article}

Keywords: Lower subtropical China, Ficus altissima, Microclimate, Leaf area index (LAI), Physiological equivalent temperature (PET)

Posted Date: November 9th, 2021

DOI: https://doi.org/10.21203/rs.3.rs-1062270/v1

License: (c) (i) This work is licensed under a Creative Commons Attribution 4.0 International License. Read Full License 


\section{Abstract}

As a widespread practice in urban landscape design, tree planting plays a vital role in improving the ecological environment and microclimate. This study obtained the physical, physiological, and meteorological data of Ficus altissima, a typical tree species in lower subtropical China, through field measurement, and analyzed its functional performance in microclimate regulation. Its results indicated that: (1) the leaf area index (LAl), sky visible factor (SVF), ground cover (GC), and other indicators of Ficus altissima had essential relationships with radiation attenuation, temperature, and humidity regulation under winter conditions in lower subtropical China; (2) there were significant differences in leaf surface temperature and transpiration between east, west, north, and south during daytime; and, (3) thermal comfort represented by physiological equivalent temperature(PET)in the shade could be expressed as functions of solar radiation (SR), mean radiation temperature (MRT), air temperature (Ta), air humidity $(\mathrm{RH})$, globe temperature $(\mathrm{Tg})$, and wind speed $(\mathrm{V})$. Based on these results, the following were the suggestions: firstly, Ficus altissima with higher LAl values should be selected for planting; secondly, trees must be planted on the east side of the site should solitary planting be undertaken to obtain maximum thermal comfort; and finally, activities under the canopy of Ficus altissima should be prioritized at 11:0016:00 during winter.

\section{Introduction}

Vegetation design is an essential method of urban landscape design, which has a vital effect on improving urban microclimate (Alchapar et al., 2017). It has a significant impact on reducing air temperature, increasing air humidity, and regulating wind fields (Crum et al., 2017). The primary body of vegetation design is trees, which have more substantial environmental improvement than shrubs and ground cover (Yang, 1994). Studying their microclimate regulation function provides designers with appropriate urban vegetation solutions (Park et al., 2012) and plays a vital function in improving urban microclimate and improving the life quality of residents (Martelli and Santos Jr, 2015).

Presently, the research of trees' effects on the surrounding microclimate has three categories: field measurements, numerical simulations, and their combination. Field measurements include accurate scale and scale model measurements, while numerical simulations are mainly performed by computer and wind tunnel experiments. Scholars worldwide utilize fixed weather stations (Shashua-Bar et al., 2011; Sanusi et al., 2016) and mobile measurements (Klemm et al., 2015) to understand the principle and mechanism of improving microclimate by trees. Some have investigated the influence of tree heightwidth ratio, combination mode, and orientation (Coutts et al., 2016; Morakinyo et al., 2017; Lee et al., 2020), while others have analyzed the influence of different canopy and planting densities under various climatic zones (De Abreu-Harbich et al., 2015; Zheng et al., 2018; Martini et al., 2020). Scaled outdoor experiments have been adopted in several studies (2020; Miao et al., 2020), which have examined the effects of urban indicators on a city thermal environment and have reported the substantial cooling potential of tree plantings on wall and air temperature (Chen et al., 2021). The numerical simulation of vegetation is primarily reflected in the change of various indicators to compare the different results and 
select the optimal scheme, including leaf area index (LAI) (Fahmy et al., 2010), leaf area density (LAD) (Li and Song, 2019), root area density (RAD) (Boukhabl and Alkam, 2012), surface vegetation cover (Li et al., 2019; Yang et al., 2019), tree coverage ratio (Chatterjee et al., 2019; Yang et al., 2019), vegetation species (Morakinyo et al., 2017), density, and arrangement (Thom et al., 2016; Lam et al., 2021). Scholars have further proposed a hybrid approach that combines wind tunnel measurement and numerical simulations to examine the effect of vegetation on a pedestrian level (Mijorski et al., 2019).

Researchers have come to varying conclusions regarding the effects of trees on microclimates from various perspective, either through measurements or simulations. Different tree types impact radiation flux in the environment due to their varying size and canopy characteristics. Different temperature gradients form in and around vegetation, and their performance varies during the day and at night. Rahman et al. (2020) compared Purple satin and Robinia pseudoacacia, and found that tree species with a higher leaf area index indicated better below-canopy surface cooling. Shahidan and Jones (2008) examined forest canopy attributes based on tropical climate conditions, and determined that a denser foliage cover and branching habit would make trees exhibit a more significant thermal radiation filter. Massetti et al. (2019) investigated the effects of a deciduous tree species (Tilia x europaea $L$ ) on surface temperature over various ground materials and on human thermal comfort, with an emphasis on tree shade variations due to leaf fall. They found that the said species had demonstrated a two-fold benefit in terms of conditions. Sabrin et al. (2021) assessed the cooling benefits of street trees in Philadelphia City, primarily considering morphological elements. They evaluated summertime thermal comfort for a city with humid subtropical climate (i.e., Philadelphia) by examining various human-biometeorological indicators like Mean-radiant temperature (Tmrt) and Physically Equivalent Temperature (PET), utilizing the Rayman model. Feng et al. (2021) found that mango tree transpiration consumed $40 \%$ (sunny) to $60 \%$ (cloudy) of a canopy's total daily energy and continued to play a role in cloudy days, making vegetation absorb the heat of surrounding air. Liu et al. (2018) conducted ENVI-MET simulation on four kinds of trees (Michelia alba, Mangifera indica, Ficus microcarpa, and Bauhinia blakeana), and identified that the model data were more stable than the measured data. Leaf surface temperature, steam flux, air temperature, and humidity were lower than the observed values.

Most domestic (China) studies have focused on the quantitative influence of certain design elements on microclimate factors, but their influence and mechanism are not sufficiently profound. There are inadequate single and multiple regression equations to depict the specific correlations among the variable (Zhuang et al., 2017). To further clarify the impact of trees on climate and human behavior, the researchers assessed five adult Ficus altissima trees in winter. The microclimate instrument measured the local microclimate data, while the principle of transpiration measured transpiration intensity in four directions. By comparing the data of measuring points in the shade and the contrast points (as exposed to the sun), the principle of Ficus altissima on the surrounding environment based on local climatic conditions was determined. Finally, the suggestions of Ficus altissima for adapting to site planting were proposed. 


\section{Methodology}

Study objects

This study focused on trees' performance in regulating microclimate. It selected Ficus trees, which thrive on the open grassland of the campus, as the primary research object. Evergreen all year round, the Ficus altissima, moraceae, Ficus genus, is a typical urban green tree species in lower subtropical China. With its thick leathery leaves, developed root system, broad crown, large tree size, and capacity for isolated planting, it can manifest an independent scenery and has a good shading effect. To study its microclimate effect, the canopy distribution, branch, leaf orientation, transpiration, shading effect, temperature, and humidity regulation of this species were evaluated.

Study area and time

Researchers took Guangdong Ocean University (110 18'32" E, 21 ${ }^{\circ} 9^{\prime} 11^{\prime \prime} \mathrm{N}$ ) in Zhanjiang (a city in China) as the study site. The site had a typical lower subtropical monsoon climate, with its most comfortable period from November to March (Luo et al., 2017). The research time was January, which typically had cloudy and sunny days, and the average daily temperature was $14-20^{\circ} \mathrm{C}$. Field measurements were performed on January 10 (cloudy day), 12 (sunny day), 13 (sunny day), and 14 (sunny day). The physical and physiological data of the plants were measured on the first two days, and the microclimate on the succeeding two days.

Table 1 Physical and physiological indicators of the trees. DBH is the diameter at breast height, LAI is the leaf area index, SVF is the visible sky factor, GC is the ground cover, and LAIDev represents the leaf distribution density within the canopy

\begin{tabular}{lllllll}
\hline Indicators & Type & \multicolumn{4}{c}{ Measuring point / No. } \\
\cline { 3 - 6 } & & 1 & 2 & 3 & 4 & 5 \\
\hline Physical indicators & DBH at 1 m (cm) & 45 & 46. & 68 & 41 & 66 \\
& Under branch height $(\mathrm{m})$ & 2.98 & 3.44 & 3.01 & 2.72 & 4.19 \\
\cline { 2 - 6 } & Canopy width $(\mathrm{m})$ & 14.07 & 10.40 & 11.80 & 9.90 & 16.10 \\
& Tree height $(\mathrm{m})$ & 12.19 & 8.45 & 9.20 & 7.64 & 13.65 \\
\cline { 2 - 6 } & Bare land diameter $(\mathrm{cm})$ & 170. & 59 & 77 & 111 & 225 \\
\hline Physiological indicators (dimensionless) & LAI & 1.989 & 1.835 & 1.876 & 1.520 & 1.815 \\
& SVF & 0.137 & 0.160 & 0.153 & 0.219 & 0.163 \\
\cline { 2 - 6 } & GC & 0.863 & 0.840 & 0.847 & 0.781 & 0.837 \\
\cline { 2 - 6 } & LAIDev & 1.083 & 1.385 & 0.913 & 0.537 & 0.731 \\
\hline
\end{tabular}

\section{Measurement items}

The researchers measured various physical indicators (Table 1), including diameter at breast height $(\mathrm{DBH})$, crown width, and tree height, which could help reflect the three dimensions of the trees and analyze the trees' impact on the environment and human behavior. In this experiment, the physical indicators of Ficus altissima were primarily obtained using a laser rangefinder (Vertex Laser Geo, Sweden), a tree girth tape (GCRAFT, China), and other instruments. Since Ficus altissima has well- 
developed roots attached to its trunk, the researchers applied estimation and difference methods to determine the pure DBH value at $1 \mathrm{~m}$ above the ground. The DBH of Ficus altissima was $41-68 \mathrm{~cm}$, and the under-branch height $(>2 \mathrm{~m})$ met the space use requirements of the active population. The crown width was 9.9-16.1 m, and the tree height was 7.64-13.65 m. Meanwhile, to assess the influence of tree shade on the underlying surface temperature, the planting sites (i.e., the range of bare land at the base of the tree trunks) were also measured.

The sky geometry, LAl, and transpiration rate of the trees were measured using the Hemi digital plant canopy analysis system (Hemi View, UK) and 1/10,000 balance scales (FA324C, China). Sky geometry and LAI were helpful to study the cover properties of plant canopy and accomplish some simple calculations. Transpiration rate aimed to reveal the absorption and release of the canopy to the environmental microclimate. The LAls of trees 1-5 were within 1.520-1.989; different degrees of LAI indicated significant differences in crown leaf densities of the five Ficus. Sky visible factor (SVF) was inversely related to LAl, with a measurement range of 0.137-0.219. LAIDev was used to interpret the density of leaf distribution within the canopy, which could evaluate the trees' growth. Ground cover (GC) intended to measure the canopy coverage to the ground, which was complementary to SVF. The combined value of the two factors should be equal to 1 ; together, they could describe the shading degree of the canopy to the ground (Table 1). Transpiration rate aimed to reveal the absorption and release of the canopy to the environmental microclimate. The dynamic changes of the leaves in four directions of Trees 3 and 4 from 8:00 to 18:00 were also measured at a one-hour sampling interval (refer to Section 3.2).

Measuring microclimatic indicators is an essential step of the experiment. Air temperature ( $\mathrm{Ta})$, relative humidity $(\mathrm{RH})$, soil temperature $(\mathrm{Ts})$, wind speed $(\mathrm{V})$, and global radiation were readily acquired by an urban multi-factor climate data acquisition instrument (HQZDZ-7, China). Globe temperature, dry bulb temperature, wet bulb temperature, and blade surface temperature were recorded using a globe thermometer, a mechanically ventilated psychrometer, and an infrared high-precision thermometer. All instruments were installed at measuring points $1.8 \mathrm{~m}$ above the ground. Regarding the trees' planting mode and distance, measuring points 1, 2, and 6 in group $A$ and 3, 4, 5, and 7 in group B were arranged under the shade of five Ficus altissima. Measuring points 6 and 7 were made the contrast points of the two groups (Fig. 1). The observation points of group A reflected the particular microclimate space formed under the canopy of Ficus altissima, while group B represented the comparison points of other group's external environment.

Calculation method

MRT is an essential influencing factor of PET, considering the influence of surrounding object surface temperature on heat dissipation from the human body and thermal comfort (Cohen et al., 2012). Tmrt $\left({ }^{\circ} \mathrm{C}\right)$ was used to represent the temperature of MRT, while globe temperature $\left(\mathrm{Tg}\right.$, in $\left.{ }^{\circ} \mathrm{C}\right)$, air temperature ( $\mathrm{Ta}$, in $\left.{ }^{\circ} \mathrm{C}\right)$, wind speed $(\mathrm{V}$, in $\mathrm{m} / \mathrm{s})$, globe emissivity ( 0.95 in this paper), and globe diameter $(\varepsilon, 0.15 \mathrm{~m}$ in this paper) needed to be considered. The formula for MRT is as follows (AC08013621, A. (Ed.), 1998): 


$$
T_{\mathrm{mrt}}=\left[\left(T_{\mathrm{g}}+273\right)^{4}+\frac{1.1 \times 10^{8} \times V^{0.6}}{\varepsilon \times D^{0.4}}\left(T_{\mathrm{g}}-T_{\mathrm{a}}\right)\right]^{0.25}-273
$$

Transpiration rate $E_{G}\left[g /\left(m^{2} \cdot h\right)\right]$ is related to transpiration rate per unit leaf area $\left[E_{L}\right.$, in $\left.g /\left(m^{2} \cdot h\right)\right]$ and $L A l$ [Eq. (2)] (Konarska et al., 2016). According to Eq. (3) (Zhu and Ping, 2013), the latent heat of evaporation $\mathrm{Q}\left[\mathrm{cal} /\left(\mathrm{m}^{2} \cdot h\right)\right]$ per unit projected area caused by tree transpiration can be computed from $\mathrm{E}_{\mathrm{G}}$ and the heat of vaporization $\lambda$. The air temperature decreased by the canopy of Ficus altissima can be determined according to Eq. (4), where $\rho$ represents the air density $\left(\mathrm{kg} / \mathrm{m}^{3}\right), \mathrm{c}$ is the specific heat capacity $\left[\mathrm{J} /\left(\mathrm{kg} \cdot{ }^{\circ} \mathrm{C}\right)\right]$,

\section{$\mathcal{V}$}

and

represents the 1000-m³ air column(Yang, 1994).

$E_{G}=E_{L} \times L A l$

$Q=E_{G} \times \lambda$

There are two ways to calculate $\lambda$ in Eq. (3): $\lambda=2498.8-2.33 T\left(\lambda\right.$, in $\mathrm{kJ} / \mathrm{kg}$; $\mathrm{T}$, in ${ }^{\circ} \mathrm{C}$ ) (Chen et al., 2019), or $\lambda=597-5 / 9 T\left(\lambda\right.$, in cal $/ \mathrm{g}$; $\mathrm{T}$, in $\left.{ }^{\circ} \mathrm{C}\right)$ (Richard $\left.\Downarrow \mathrm{L} ., 1986\right)$.

$$
\Delta T=\frac{Q}{\rho X C X V}
$$

Table 2 Ranges of the thermal indices of PET for different grades of thermal perception by human beings and their physiological stress (Matzarakis et al., 1999)

\begin{tabular}{ccc}
\hline $\mathrm{PET} \square^{\circ} \mathrm{C} \square$ & Thermal perception & Grade of physiological stress \\
\hline$\square 4$ & Very cold & Extreme cold stress \\
$4-8$ & Cold & Strong cold stress \\
$8-13$ & Cool & Moderate cold stress \\
$13-18$ & Slightly cool & Slight cold stress \\
$18-23$ & Comfortable & No thermal stress \\
$23-29$ & Slightly warm & Slight heat stress \\
$29-35$ & Warm & Moderate heat stress \\
$35-41$ & Hot & Strong heat stress \\
$\square 41$ & Very hot & Extreme heat stress \\
\hline
\end{tabular}

The main models and indices for evaluating outdoor thermal comfort include physiological equivalent temperature (PET) (Cohen et al., 2012; Kántor et al., 2016), COMFA model (Stocco et al., 2015), index of thermal stress (ITS) (Massetti et al., 2019), universal thermal climate index (UTCI) (Coutts et al., 2016), standard effective model SET (SET*)(Hsieh et al., 2016), and predicted mean vote (PMV) (Sun et al., 
2018). In this study, PET was selected as an objective evaluation index of the impact of Ficus altissima on outdoor thermal comfort. Table 2 defines the detailed evaluation interval. PET calculated the measured microclimate factors by substituting them into the Rayman software. Meanwhile, the human body indicators were set as male, 175-cm height, 20 years old, $65-\mathrm{kg}$ weight, 1.0 thermal resistance of winter clothing, and $80 \mathrm{~W} / \mathrm{m}^{2}$ metabolic rate of activity (Zhang and Wang, 2017).

\section{Experimental Results And Discussion}

Radiation attenuation and related indicators

Comparison points 6 (a, Fig. 2) and 7 (b, Fig. 2) exhibited the highest radiation values during daytime because they were exposed to the sun. The variation rule of the total radiation values of the measurement points (1-5) under the shade was consistent with the comparison points. The overall trend gradually rose from morning to noon, reaching its peak at 12:00-14:00, then gradually decreased. By comparing the radiation values of the measurement points under the shade, when LAI was not differentiated, the smaller the tree, the better the protection from the sun. Thus, the group A measurement point 1 was smaller than point 2. However, when there were significant differences in LAl of group B, measurement point 3 with higher LAl values had significant shade and presented lower radiation, while measurement point 4 with lower LAl values exhibited poor shade and manifest higher radiation.

Canopy occlusion is closely related to LAI. Higher LAI values and lower transmissivity percentage value corresponds to a higher radiation filtration percentage. The higher the LAI value, the lower the transmittance percentage value and the higher the corresponding radiation filtering percentage. It implies that LAl values that are greater than five can approximately filter more than $90 \%$ of radiation, while approximately $70-90 \%$ filtration occurs when LAl is below five (Shahidan and Jones, 2008). This study found that the filtered radiation percentages of the five trees were $90.7 \%, 87.9 \%, 90 \%, 82.2 \%$, and $85 \%$, respectively, indicating that Ficus altissima canopies could effectively filter solar radiation, and that radiation blocking was in direct proportion to LAI. The relationship between the variables is as follows:

$\Delta l=927 L A I-1377, R^{2}=0.979$

Where $\Delta \mathrm{l}$ is the canopy filtering radiation value, in $\mathrm{W} / \mathrm{m}^{2}$.

The canopy filters solar radiation waves and lowers the average radiation temperature below the canopy (Kotzen, 2003). The mean radiation temperature (MRT) of the shade measuring points significantly decreased, while the maximum daytime radiation decreased by $34.2-37.2^{\circ} \mathrm{C}$ in group $\mathrm{A}$ and $9.1-27.7^{\circ} \mathrm{C}$ in group B. The diurnal MRT effectively separated by tree canopy was $6.4-25.7 \%$. The relationship between canopy blocking radiation $(\Delta \mathrm{I})$ and MRT drop ( $\Delta \mathrm{Tmrt})$ is as follows:

$\Delta T m r t=0.034 \Delta l+4.975, R^{2}=0.554$ 
Canopy SVF values were obtained from the elevation angle, indicating the proportion of the sky seen through the canopy. The value ranges from 0 to 1; 1 represents a complete sky, while 0 represents complete occlusion. The smaller the value, the thicker the canopy, hence less radiation transmitted and greater radiation attenuation. GC is the opposite of SVF, where the value was obtained from the overlooking angle, and the sum would equal to 1 . The measured results indicated that the radiation attenuation of the Ficus altissima canopy had the following linear relationship with SVF and GC:

$\Delta l=-5196.21 S V F+1163.649, R^{2}=0.921(7)$

$\Delta /=5196.21 G C-4032.561, R^{2}=0.921(8)$

LAIDev was used to reflect whether the canopy distribution was uniform and whether the thickness of each direction was consistent, requiring high quality of the pictures shot. Photos were taken in the morning, evening, or cloudy days when the light was mild; the images were preprocessed through a canopy analysis software. The threshold was set at around 150. The LAIDev value is significantly influenced by manual operation, making it easy to produce errors. To avoid excessive errors, five photos for each tree were taken at different periods. The obtained LAIDev value has a specific correlation with radiation attenuation:

$\Delta /=-1294.795 L A I D e v^{2}+2856.625 L A I D e v-1127.705, \mathrm{R}^{2}=0.795(9)$

Transpiration and cooling

Due to variations of solar altitude angle, there were significant differences in the temperature data of the four directions of the tree crown (Fig. 3). Under the influence of climatic conditions in the lower subtropical region, the highest daytime temperature $\left(12.3-33.6^{\circ} \mathrm{C}\right)$ and maximum temperature difference $\left(21.3^{\circ} \mathrm{C}\right)$ were found in the southern leaves of Ficus altissima in winter, while the northerly leaf temperature was at its lowest in daytime $\left(12.1-19.4^{\circ} \mathrm{C}\right)$ and the temperature difference was the lowest $\left(6.7^{\circ} \mathrm{C}\right)$. The eastern and western temperature ranges were in the middle, but there was a difference in time dimension. The temperature of the eastern leaf began to rise sharply at 10:00 and sustained its peak at 17:00. On the other hand, the leaf temperature on the west side significantly rose at 13:00 and sustained its peak at 17:00. It indicated that the leaf temperature on the east side reached its peak earlier, while the peak time was longer than that on the west side. Additionally, the temperature variations of the leaves in the four directions were affected by solar radiation, consistent with the distribution trend of radiation. Several peaks $(10: 00,13: 00$, and 16:00) and troughs $(12: 00,15: 00)$ emerged in the leaf temperatures at four directions of Tree 3. Meanwhile, the measured total radiation values at comparison point 6 increased and decreased correspondingly. The peak at Tree 4 appeared from 13:00 to 15:00, while the measured total radiation value at comparison point 7 likewise reached the maximum range.

Regarding calculating transpiration rate per unit leaf area (Fig. 4), No. 3 Ficus altissima with a higher LAI value had the strongest transpiration on the southward leaf in the morning [mean $28.79 \mathrm{~g} /\left(\mathrm{m}^{2} \cdot \mathrm{h}\right)$ ], and the strongest transpiration on the westward leaf in the afternoon [mean $\left.30.23 \mathrm{~g} /\left(\mathrm{m}^{2} \cdot \mathrm{h}\right)\right]$. The mean 
transpiration rate on the southward leaf was the highest throughout the day $\left[23.54 \mathrm{~g} /\left(\mathrm{m}^{2} \cdot \mathrm{h}\right)\right]$. No. 4 Ficus altissima with a lower LAl value had the maximum transpiration rate in the west direction [mean 23.33 $\left.\mathrm{g} /\left(\mathrm{m}^{2} \cdot \mathrm{h}\right)\right]$. Leaf transpiration rate at all directions reached a low point at 13:00, mainly due to stomatal closure as a consequence of heat. LAI and the four directions were considered to calculate the transpiration rate of the entire plant; the results indicated that the transpiration rate of Ficus altissima with higher LAl was relatively stable, while that with lower LAI fluctuated violently due to the influence of solar radiation; moreover, the transpiration rate in the afternoon was significantly lower than that in the morning. The standard deviation and variance on the west side were the largest, indicating that the latent heat of hourly evaporation was significantly different from the mean value; that is, data fluctuation was the most severe. The standard deviation and variance of the north side were the smallest, signifying that the hourly latent heat of evaporation on this side was closest to the mean value; that is, the data change was most stable.

Table 3 Description statistics of the latent heat of evaporation and transpiration cooling of Ficus altissima. Q represents the latent heat of evaporation in the four directions of east, west, north, and south, while $\triangle \mathrm{T}$ denotes the cooling changes caused by transpiration in those directions

\begin{tabular}{llllllll}
\hline Indicators & $\begin{array}{l}\text { Minimum } \\
\text { Statistic }\end{array}$ & $\begin{array}{l}\text { Maximum } \\
\text { Statistic }\end{array}$ & $\begin{array}{l}\text { Mean } \\
\text { Statistic }\end{array}$ & $\begin{array}{l}\text { Mean } \\
\text { Error }\end{array}$ & $\begin{array}{l}\text { Std. } \\
\text { Std. } \\
\text { Statistic }\end{array}$ & Deviation & $\begin{array}{l}\text { Variance } \\
\text { Statistic }\end{array}$ \\
\hline $\mathrm{Q}_{\mathrm{E}}$ & 37.0 & 399.1 & 177.19 & 23.10 & 108.33 & 11736.42 \\
$\mathrm{Q}_{\mathrm{W}}$ & 56.0 & 506.0 & 227.86 & 29.86 & 140.08 & 19621.94 \\
$\mathrm{Q}_{\mathrm{S}}$ & 61.2 & 428.7 & 218.70 & 25.59 & 120.02 & 14405.33 \\
\hline $\mathrm{Q}_{\mathrm{N}}$ & 32.1 & 352.4 & 167.98 & 18.74 & 87.88 & 7723.55 \\
\hline$\triangle \mathrm{T}_{\mathrm{E}}$ & 0.1 & 1.3 & 0.60 & 0.08 & 0.36 & 0.13 \\
\hline$\triangle \mathrm{T}_{\mathrm{W}}$ & 0.2 & 1.7 & 0.76 & 0.10 & 0.47 & 0.22 \\
\hline$\triangle \mathrm{T}_{\mathrm{S}}$ & 0.2 & 1.4 & 0.73 & 0.09 & 0.40 & 0.16 \\
\hline$\triangle \mathrm{T}_{\mathrm{N}}$ & 0.1 & 1.2 & 0.56 & 0.06 & 0.29 & 0.09 \\
\hline
\end{tabular}

Cooling caused by leaf transpiration can be expressed as the latent heat of evaporation Q (Table 3) to calculate the cooling of surrounding air due to the tree canopy (refer to formula 2-4). The study indicated that the maximum evaporation latent heat of Ficus altissima was located in the west $\left(506 \mathrm{Cal} \cdot \mathrm{m}^{-2} \cdot \mathrm{H}^{-1}\right)$, and the minimum value was located in the north $\left.\left[352.4 \mathrm{Cal} \cdot \mathrm{m}^{-2} \cdot \mathrm{H}^{-1}\right)\right]$. Transpiration can bring about significant environmental cooling, especially in the west, with a range of $0.2-1.7^{\circ} \mathrm{C}(\triangle T)$ and an average temperature drop of $0.76^{\circ} \mathrm{C}$ during the day. Transpiration in the north was the weakest, with a cooling range of $0.1-1.2^{\circ} \mathrm{C}$. The variation of temperature drop data was consistent with that of latent heat of evaporation, with the most apparent fluctuation on the west side and the most stable on the north side. To summarize, the effect of heat evaporation and cooling on leaves of Ficus altissima was the most obvious on the west side, followed by the south, east, and north sides.

Adjusting ambient humidity 
Transpiration from the tree canopy moves water into the air, thus increasing ambient humidity (Kántor et al., 2016). During sunny days in winter, the average humidity at the measurement points under the shade from point 1 to 5 was $36.4 \%, 35.2 \%, 32.38 \%, 31.63 \%$, and $32.3 \%$, respectively, while those of comparison points $6-7$ were $33.59 \%$ and $31.13 \%$. Ficus altissima enhanced air humidity, effectively humidifying $3 \%$ (group A) to $5 \%$ (group B). The relative humidity at measurement points 1 to 5 was low at noon and high in the morning and evening, but compared with comparison points 6 and 7, the most apparent humidification period was at 12:00-15:00 (Fig. 5). The difference in air humidity in group A was more prominent than in group B, primarily caused by the canopy with higher LAI. Measurement point 1 with the highest LAI was most capable of improving environmental humidity, while measurement point 4 with the lowest LAI was the weakest, indicating that LAI was directly proportional to environmental humidity. The variation ranges of daytime humidity at measuring points 1 and 2 in group A were $40.3 \%$ and $45.7 \%$, respectively, while those in group $B$ were $41.3 \%, 46.2 \%$, and $42.9 \%$, respectively. The measurement points with stable humidity changes had larger LAl, GC, canopy, tree height, and smaller SVF values; the higher the tree shape, the thicker the shade, the wider the canopy, and the more stable the shade air humidity.

Affected by canopy shade, the underlying surface-soil moisture of the shade measuring points was more stable and slightly changed the daytime humidity value. Unlike the variation rule of air humidity, the soil humidity of the measuring points under the shade would slightly rise at noon, and the degree of rise was less than that of the exposed soil. Changes in soil moisture were related to certain physiological and physical indicators of trees. The internal comparison results of groups A and B indicated that larger LAl, GC, canopy, tree height, and smaller SVF were conducive to moisture preservation of the underlying surface. Fig. 6 illustrates that the variation range of soil moisture in the shade measuring point of group $A$ was $1.3-1.7 \%$, and that of soil moisture underexposure was $2.4 \%$.

Moreover, the variation range of soil moisture in the shade measuring points of group B was $1.7-2.0 \%$, and the variation range of soil moisture underexposure was $2.3 \%$. Compared to points 6 and 7, the underlying surface humidity of group $A$ was greater than that of group $B$ when the soil moisture changes were almost the same, primarily because group A had a thicker canopy to shade the bare land below. Likewise, humidity fluctuation at all measuring points in group A was smaller than that in group B, proving that tall and vigorous trees were more conducive to sustaining the humidity of the underlying surface.

Thermal comfort analysis

PET was used to study the effect of Ficus altissima on thermal comfort and explored the relationship between PET and multiple climate factors (e.g., Sr, Tmrt, and Ta). Fig. 7 indicated that the maximum PET value at shade measuring points 1-5 was lower than that at comparison points 6-7 under sunny weather in winter (the maximum difference was 16.3); moreover, the variation range of PET in the shade measuring point was relatively gentle. From 8:00 to 9:00, it was in a cold and cool state under the shade. From 9:00 to 10:00, it was generally in a slightly cool state. From 10:00, PET sharply increased at all measuring points, and some measuring points crossed three intervals. Since 16:00, the PET of all 
measuring points sharply decreased, and some of the measuring points decreased by three intervals. By 18:00, all measuring points returned to a cold and cool state. The optimum range for being or receiving comfortable primarily focused on 11:00-16:00. For group A with a low SVF and high LAI, PET was primarily located in a slightly cool (close to comfortable) interval; for group B with a relatively high SVF and low LAI, PET was primarily located in a comfortable interval. All shade measuring points were two to three intervals lower than the comparison points. The comparison points were in a slightly warm or warm range for most of the time (six to seven hours), while the shade measuring points were within or close to the comfortable range for most of the time (five hours). The results showed that the shade of Ficus altissima in winter could impact the human body's comfort and make people exercise for most of the day in a relatively comfortable thermal environment.

The correlation between PET and climate factors could be tested using Pearson correlation. The results indicated that PET was significantly correlated with total solar radiation $(R=0.829)$, average radiation temperature $(R=0.946)$, air temperature $(R=0.754)$, air humidity $(R=-0.674)$, globe temperature $(R=$ $0.975)$, and wind speed $(R=0.360)$, all significant at a 0.01 level, and could be expressed by multiple regression models (Fig. 8). According to the expression of a regression model, PET was positively correlated with Sr, Tmrt, Ta, Tg, V, and negatively correlated with Rh. From the model, Tmrt, Tg, and PET had a high linear fitting degree, and R-square values were 0.895 and 0.951 , respectively. The smallest $R-$ square was the regression model of PET and $\mathrm{V}$, at only 0.13 . The degree of data dispersion was high and the degree of linear fitting was low.

\section{Conclusions}

Considering the growth properties and site effects of Ficus altissima in lower subtropical China, this paper implemented climate measurement work and combined the microclimate principle with the growth rule of trees. The fundamental findings are as provided below.

Firstly, physical and physiological indicators are essential indicators for quantifying the effects of trees on the environment, and they are associated with radiation attenuation, transpiration, temperature change, humidity regulation, and PET improvement. LAI, SVF, GC, and LAIDev of different values significantly correlated with radiation attenuation, as expressed by Formulae $5,7,8$, and 9 . Studies have shown that a larger LAI, GC, canopy, and tree height denote a smaller SVF value; hence, the more air humidity can be improved (humidification was $3-5 \%$ ), as well as the moisture of the underlying surface (humidity variation was less than $2 \%$ ). There was no noticeable difference in LAl. The smaller the tree height, the better it was to block solar radiation. Moreover, the higher the LAl, the more stable the transpiration performance. A higher LAI value could cause a significant transpiration cooling on the west side of the tree crown, which could reach $1.7^{\circ} \mathrm{C}$. When LAl was between $1.520-1.989$, the air could be effectively humidified by $3-5 \%$. In addition, when SVF was high and LAI was low, PET tended to develop in the comfort zone. 
Secondly, the four directions of trees were affected by solar radiation to varying degrees, such that there were significant differences in leaf surface temperature and transpiration in different directions. For leaf surface temperature, the northerly leaf exhibited the most stability, while the southerly average temperature and temperature difference altered the most; the leaf temperature in the east reached the peak earlier, while its peak time was longer than that in the west. For transpiration rate, the transpiration rates in the west and south directions were better than those in the east and north directions. Influenced by LAl, the side with the maximum transpiration rate was located in the middle and afternoon, which could change (for example, No. 3 Ficus altissima had the strongest transpiration southward in the morning and westward in the afternoon). For transpiration cooling, it was most significant in the west, with a cooling range of $0.2-1.7^{\circ} \mathrm{C}$. Transpiration on the north side was the weakest, with a cooling range of $0.1-1.2^{\circ} \mathrm{C}$. For evaporation latent heat, the maximum value for Ficus altissima was located in the west $\left[506 \mathrm{cal} /\left(\mathrm{m}^{2} \cdot \mathrm{h}\right)\right]$, and the minimum value was located in the north $\left[352.4 \mathrm{cal} /\left(\mathrm{m}^{2} \cdot \mathrm{h}\right)\right]$.

Thirdly, in terms of thermal comfort, the differences between the shade measuring points and the open location points were compared, and significant correlations between several indicators and PET were explored (Fig. 8). In winter, the shade of Ficus altissima can improve human comfort and make people in motion in a relatively relaxed state.

Combined with the influence of thermal comfort(expressed by PET) and other climate factors, the following are the landscape design suggestions. (1) In terms of seedling selection, Ficus altissima with significant LAI value, high volume, and lush growth should be selected for planting as far as possible due to its relatively stable climate regulation function. (2) Ficus altissima has a noticeable transpiration effect and has the most significant influence on the west side. Therefore, it must be planted on the east side of the activity site in isolation so that the canopy can portray its best thermal comfort regulation function. (3) During winter in lower subtropical China, the function of Ficus altissima leaves in regulating temperature at noon and afternoon is not as good as in the morning and evening, but they can still maintain a comfortable microclimate under the tree canopy. Moreover, the activities under the shade should be arranged at noon and afternoon (11:00-16:00) in the design.

\section{References}

1. International Organization for Standardization (1998) Ergonomics of the Thermal Environment: Instruments for Measuring Physical Quantities. ISO

2. Alchapar NL, Pezzuto CC, Correa EN, Chebel-Labaki L (2017) The impact of different cooling strategies on urban air temperatures: the cases of Campinas, Brazil and Mendoza, Argentina. Theoretical and Applied Climatology 130:35-50. https://doi.org/10.1007/s00704-016-1851-5

3. Boukhabl M, Alkam D (2012) Impact of vegetation on thermal conditions outside, Thermal modeling of urban microclimate, Case study: the street of the republic, Biskra. Energy Procedia 18:73-84. https://doi.org/10.1016/j.egypro.2012.05.019 
4. Chatterjee S, Khan A, Dinda A, Mithun S, Khatun R, Akbari., Kusaka H, Mitra C, Bhatti SS, Van-Doan Q (2019) Simulating micro-scale thermal interactions in different building environments for mitigating urban heat islands. Science of the Total Environment 663:610-631.

https://doi.org/10.1016/j.scitotenv.2019.01.299

5. Chen T, Pan H, Lu M, Hang J, Lam CKC, Yuan C, Pearlmutter D (2021) Effects of tree plantings and aspect ratios on pedestrian visual and thermal comfort using scaled outdoor experiments. Science of the Total Environment 801:20. https://doi.org/10.1016/j.scitotenv.2021.149527

6. Chen X, Zhao P, Hu Y, Ouyang L, Zhu L, Ni G (2019) Canopy transpiration and its cooling effect of three urban tree species in a subtropical city- Guangzhou, China. Urban Forestry \& Urban Greening 43:126368. https://doi.org/10.1016/j.ufug.2019.126368

7. Cohen P, Potchter O, Matzarakis A (2012) Daily and seasonal climatic conditions of green urban open spaces in the Mediterranean climate and their impact on human comfort. Building and Environment 51:285-295. https://doi.org/10.1016/j.buildenv.2011.11.020

8. Coutts AM, White EC, Tapper NJ, Beringer J, Livesley SJ (2016) Temperature and human thermal comfort effects of street trees across three contrasting street canyon environments. Theoretical and Applied Climatology 124:55-68. https://doi.org/10.1007/s00704-015-1409-y

9. Crum SM, Shiflett SA, Jenerette GD (2017) The influence of vegetation, mesoclimate and meteorology on urban atmospheric microclimates across a coastal to desert climate gradient. Journal of Environmental Management 200:295-303.

https://doi.org/10.1016/j.jenvman.2017.05.077

10. De-Abreu-Harbich LV, Labaki LC, Matzarakis A (2015) Effect of tree planting design and tree species on human thermal comfort in the tropics. Landscape and Urban Planning 138:99-109. https://doi.org/10.1016/j.landurbplan.2015.02.008

11. Fahmy M, Sharples S, Yahiya M (2010) LAl based trees selection for mid latitude urban developments: A microclimatic study in Cairo, Egypt. Building and Environment 45:345-357. https://doi.org/10.1016/j.buildenv.2009.06.014

12. Feng XM, Zhang YF,Xu GY,Huang CY,He CD (2021) Energy balance observation and sensible heat model optimization for urban tree canopy in the hot-humid region. Building Science 37(4):168-179 (in Chinese). https://doi.org/10.13614/j.cnki.11-1962/tu.2021.04.23

13. Hsieh CM, Jan FC, Liman Z (2016) A simplified assessment of how tree allocation, wind environment, and shading affect human comfort. Urban Forestry \& Urban Greening 18:126-137. https://doi.org/10.1016/j.ufug.2016.05.006

14. Kántor N, Kovács A, Takács Á (2016) Small-scale human-biometeorological impacts of shading by a large tree. Open Geosciences 8:231-245. https://doi.org/10.1515/geo-2016-0021

15. Klemm W, Heusinkveld BG, Lenzholzer S, Jacobs MH, Van-Hove B (2015) Psychological and physical impact of urban green spaces on outdoor thermal comfort during summertime in The Netherlands. Building and Environment 83:120-128. https://doi.org/10.1016/j.buildenv.2014.05.013 
16. Konarska J, Uddling J, Holmer B, Lutz M, Lindberg F, Pleijel H, Thorsson S (2016) Transpiration of urban trees and its cooling effect in a high latitude city. International Journal of Biometeorology 60:159-172. https://doi.org/10.1007/s00484-015-1014-x

17. Kotzen B (2003) An investigation of shade under six different tree species of the Negev desert towards their potential use for enhancing micro-climatic conditions in landscape architectural development. Journal of Arid Environments 55:231-274. https://doi.org/10.1016/S01401963(03)00030-2

18. Lam CKC, Lee H, Yang SR, Park S (2021) A review on the significance and perspective of the numerical simulations of outdoor thermal environment. Sustainable Cities and Society 71:102971. https://doi.org/10.1016/j.scs.2021.102971

19. Lee $\mathrm{H}$, Mayer $\mathrm{H}$, Kuttler $\mathrm{W}$ (2020) Impact of the spacing between tree crowns on the mitigation of daytime heat stress for pedestrians inside EW urban street canyons under Central European conditions. Urban Forestry \& Urban Greening 48:126558. https://doi.org/10.1016/j.ufug.2019.126558

20. Lee R (1978) Forest Microclimatology. Columbia University Press. New York

21. Li K, Liu X, Zhou J (2019) Impact of environmental characteristics in urban green spaces on outdoor thermal environment: A case study of Wuhan City, China. Indoor and Built Environment 28:12171236. https://doi.org/10.1177/1420326X19867378

22. Li Y, Song Y (2019) Optimization of vegetation arrangement to improve microclimate and thermal comfort in an urban park. International Review for Spatial Planning and Sustainable Development 7:18-30. https://doi.org/10.14246/irspsd.7.1_18

23. Liu Z, Zheng S, Zhao L (2018) Evaluation of the ENVI-Met vegetation model of four common tree species in a subtropical hot-humid area. Atmosphere, 9(5):198.

https://doi.org/10.3390/atmos9050198

24. Luo S, Chen D, Chen H, Zhou Y (2017) Analysis and evaluation on the tourism climate comfort degree in Zhanjiang city from 1986 to 2016 . Journal of Lingnan Normal University 38:147-153 (in Chinese)

25. Martelli A, Santos-Jr AR (2015) Urban tree of Itapira-SP: perspective for environmental education and its influence on thermal comfort. Electronic Journal in Management, Education and Environmental Technology 19:1018-1031

26. Martini A, Biondi D, Batista AC (2020) Thermal comfort provided by street trees in cities. Arboricultural Journal 42:153-164. https://doi.org/10.1080/03071375.2020.1755187

27. Massetti L, Petralli M, Napoli M, Brandani G, Orlandini S, Pearlmutter D (2019) Effects of deciduous shade trees on surface temperature and pedestrian thermal stress during summer and autumn. International Journal of Biometeorology 63:467-479. https://doi.org/10.1007/s00484-019-01678-1

28. Matzarakis A, Mayer H, Iziomon M (1999) Applications of a universal thermal index: Physiological equivalent temperature. International Journal of Biometeorology 43:76-84.

https://doi.org/10.1007/s004840050119

Page $14 / 21$ 
29. Miao S, Jiang W, Liang P, Liu H, Wang X, Tan J, Zhang N, Li J, Du W, Pei L (2020) Advances in Urban Meteorological Research in China. Journal of Meteorological Research 34:218-242. https://doi.org/10.1007/s13351-020-9858-3

30. Mijorski S, Cammelli S, Green J (2019) A hybrid approach for the assessment of outdoor thermal comfort. Journal of Building Engineering 22:147-153. https://doi.org/10.1016/j.jobe.2018.12.003

31. Morakinyo TE, Kong L, Lau K, Chao Y, Ng E (2017) A study on the impact of shadow-cast and treespecies on in-canyon and neighborhood's thermal comfort. Building and Environment 115:1-17. https://doi.org/10.1016/j.buildenv.2017.01.005

32. Park M, Hagishima A, Tanimoto J, Narita KI (2012) Effect of urban vegetation on outdoor thermal environment: field measurement at a scale model site. Building and Environment 56:38-46. https://doi.org/10.1016/j.buildenv.2012.02.015

33. Rahman MA, Hartmann C, Moser-Reischl A, Von-Strachwitz MF, Paeth H (2020) Tree cooling effects and human thermal comfort under contrasting species and sites. Agricultural and Forest Meteorology, 287:107947. https://doi.org/10.1016/j.agrformet.2020.107947

34. Sabrin S, Karimi M, Nazari R, Pratt J, Bryk J (2021) Effects of Different Urban-Vegetation Morphology on the Canopy-level Thermal Comfort and the Cooling Benefits of Shade Trees: Case-study in Philadelphia. Sustainable Cities and Society, 66:102684. https://doi.org/10.1016/j.scs.2020.102684

35. Sanusi R, Johnstone D, May P, Livesley SJ (2016) Street orientation and side of the street greatly influence the microclimatic benefits street trees can provide in summer. Journal of Environmental Quality 45:167-174. https://doi.org/10.2134/jeq2015.01.0039

36. Shahidan MF, Jones P (2008) Plant Canopy Planting Design in Modifying Urban Thermal Environment: Theory and Guidelines. 25th Conference on Passive and Low Energy Architecture-PLEA 2008:179

37. Shashua-Bar L, Pearlmutter D, Erell E (2011) The influence of trees and grass on outdoor thermal comfort in a hot-arid environment. International Journal of Climatology 31:1498-1506. https://doi.org/10.1002/joc.2177

38. Stocco S, Cantón MA, Correa EN (2015) Design of urban green square in dry areas: Thermal performance and comfort. Urban Forestry \& Urban Greening 14:323-335. https://doi.org/10.1016/j.ufug.2015.03.001

39. Sun S, Huang K, Hu Y, Xing Z, Su Q (2018) Analysis of Application of Environmental Engineering Construction in Ecological City. Smart Construction Research 2:1-5

40. Thom JK, Coutts AM, Broadbent AM, Tapper NJ (2016) The influence of increasing tree cover on mean radiant temperature across a mixed development suburb in Adelaide, Australia. Urban Forestry \& Urban Greening 20:233-242. https://doi.org/10.1016/j.ufug.2016.08.016

41. Yang $S$ (1994) A study on the effect of decreasing temperature and increasing humidity of urban afforestation trees. Geographical research 13:74-80 (in Chinese)

42. Yang Y, Zhou D, Wang Y, Ma D, Chen W, Xu D, Zhu Z (2019) Economical and outdoor thermal comfort analysis of greening in multistory residential areas in Xi'an. Sustainable Cities and Society 
51:101730. https://doi.org/10.1016/j.scs.2019.101730

43. Zhang DS, Wang Z (2017) Micro-climate effect and human thermal comfort of square canopy in dense habitat - a case study of Shanghai knowledge and innovation community square. Chinese Landscape Architecture 33:18-22 (in Chinese)

44. Zheng S, Guldmann JM, Liu Z, Zhao L (2018) Influence of trees on the outdoor thermal environment in subtropical areas: An experimental study in Guangzhou, China. Sustainable Cities and Society 42:482-497. https://doi.org/10.1016/j.scs.2018.07.025

45. Zhu LW, Ping Z (2013) Temporal variation in sap-flux-scaled transpiration and cooling effect of a subtropical Schima superba plantation in the urban area of Guangzhou. Journal of Integrative Agriculture 12:1350-1356. https://doi.org/10.1016/S2095-3119(13)60548-1

46. Zhuang XL, Duan YX, Jin HX (2017) Research review on urban landscape micro-climate. Chinese Landscape Architecture 33:23-28 (in Chinese)

47. Ziter CD, Pedersen EJ, Kucharik CJ, Turner MG (2019) Scale-dependent interactions between tree canopy cover and impervious surfaces reduce daytime urban heat during summer. P. Natl.

Proceedings of the National Academy of Sciences 116:7575-7580.

https://doi.org/10.1073/pnas.1817561116

\section{Declarations}

\section{Acknowledgments}

We thank all the workers and volunteers from Guangdong Ocean University. They are: Shengyi Xu, Jiahao Xu, Qianhong Chen, Shanshan Zheng, Meiyan Zhu, Simin Fu, Mu Chen, Guangren Mai, Xiaoyin Shi, Minyi Yuan and Zhuohang Zhong.

\section{Author contributions}

All authors contributed to the study conception and design. Material preparation, paper writing and type setting were performed by WD. Manuscript revision, data review and translation proofreading were worked by $\mathrm{CX}$ and $\mathrm{YJ}, \mathrm{JC}$ organized outdoor measurement and mainly responsible for data analysis.

\section{Funding}

This research was supported by innovation training program for college students: study on thermal comfort of plant landscape in tropical coastal campus 570119042, teaching reform project: teaching research on local architectural structure and construction based on tropical climate characteristics 570219082, and PhD Start-up Funds 060302052101.

\section{Compliance with ethical standards}

\section{Conflict of interest}


The authors declare that they have no known competing financial interests or personal relationships that could have appeared to influence the work reported in this paper.

\section{Figures}
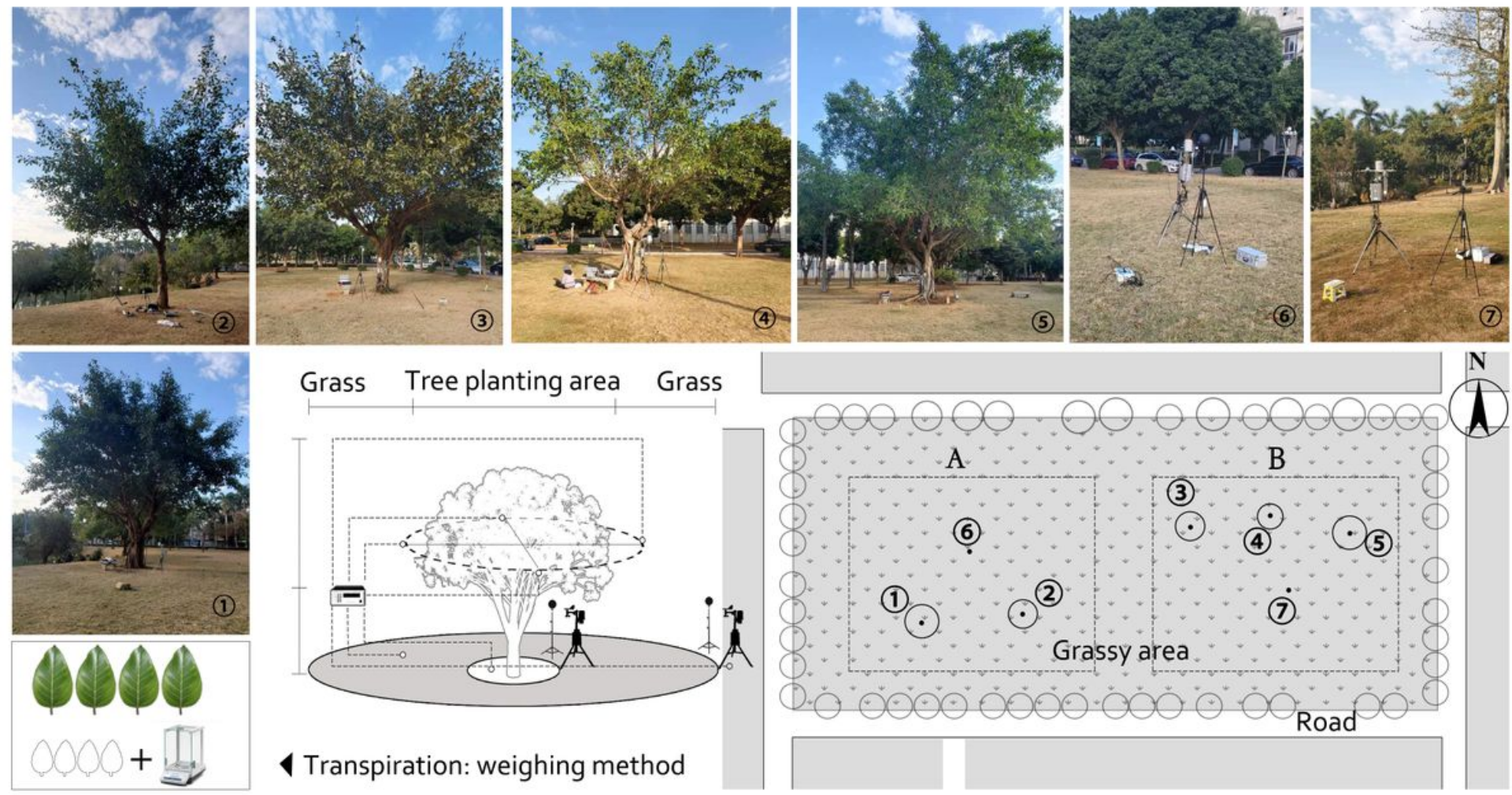

\section{Figure 1}

Climate data collection and analysis for Ficus altissima. $\mathbb{\nabla} \nabla$ represented the location of each measuring point and the field condition of the measured day, respectively. The measured time of measuring points $\nabla$, $\nabla, \nabla, \nabla$, and $\nabla$ was January 13,2021 , while the measured times of measuring points $\nabla$ and $\otimes$ were January 13 and 14,2021

\section{a:Group A}

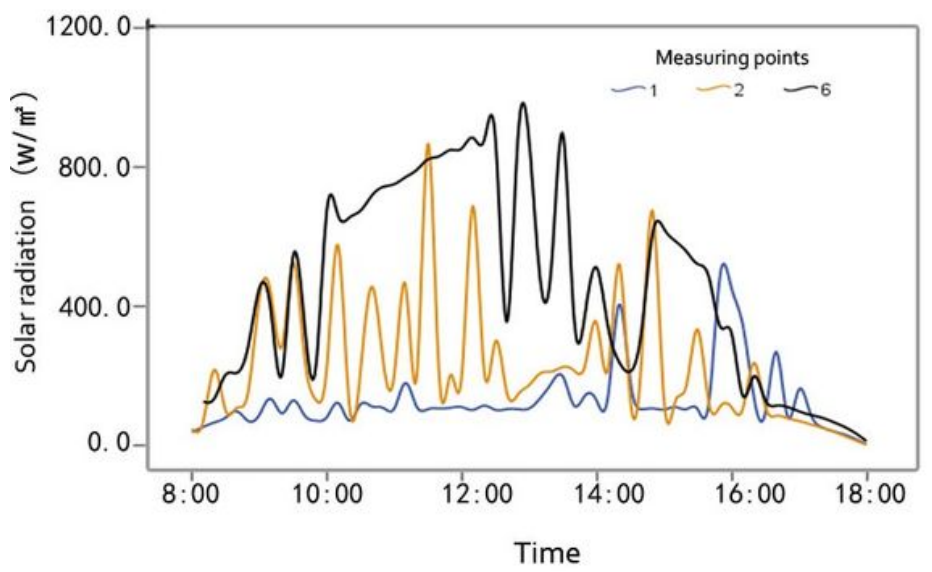

b:Group B

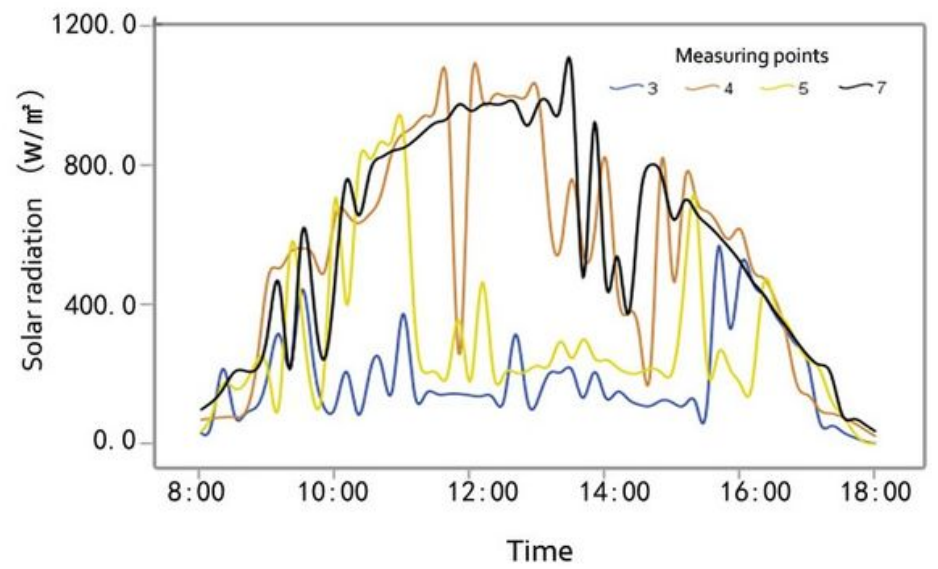


Figure 2

Solar radiation of groups A and B, the data was measured on January 13, 2021
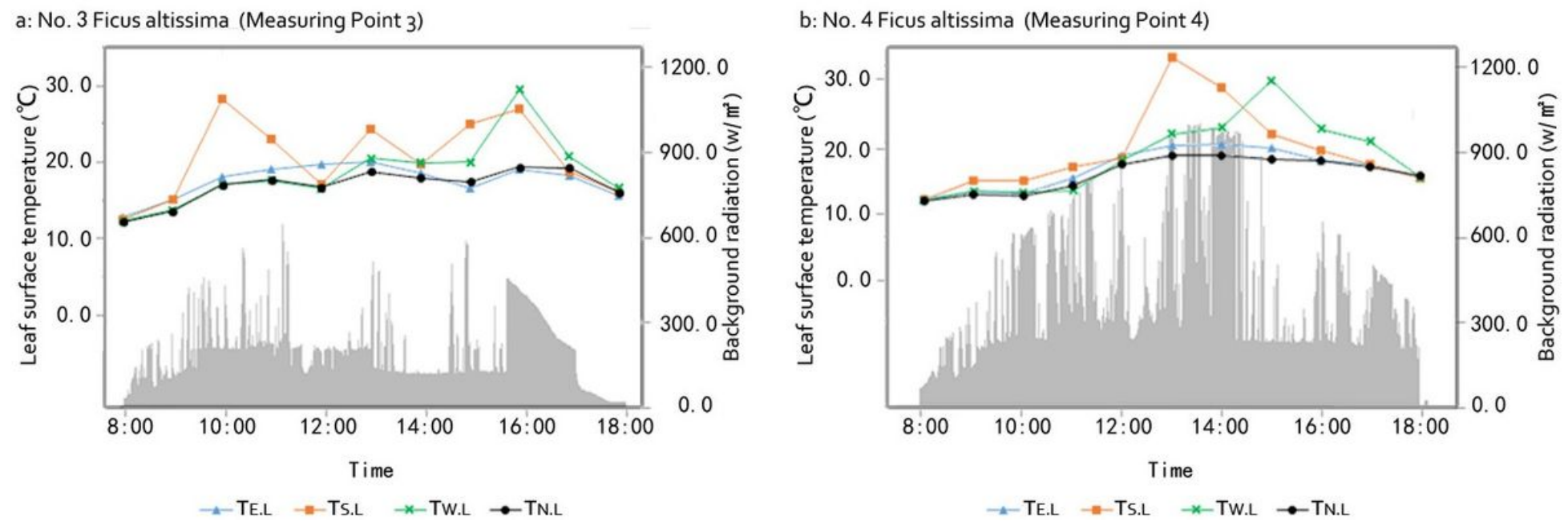

Figure 3

Leaf surface temperature distribution at points 3 and 4 was measured on January 14, 2021. TE.L, TS.L, TW.L, and TN.L represent leaf surface temperature in the east, south, west, and north directions, respectively. The gray shade represents the background radiation

a: No. 3 Ficus altissima (Measuring point 3 )

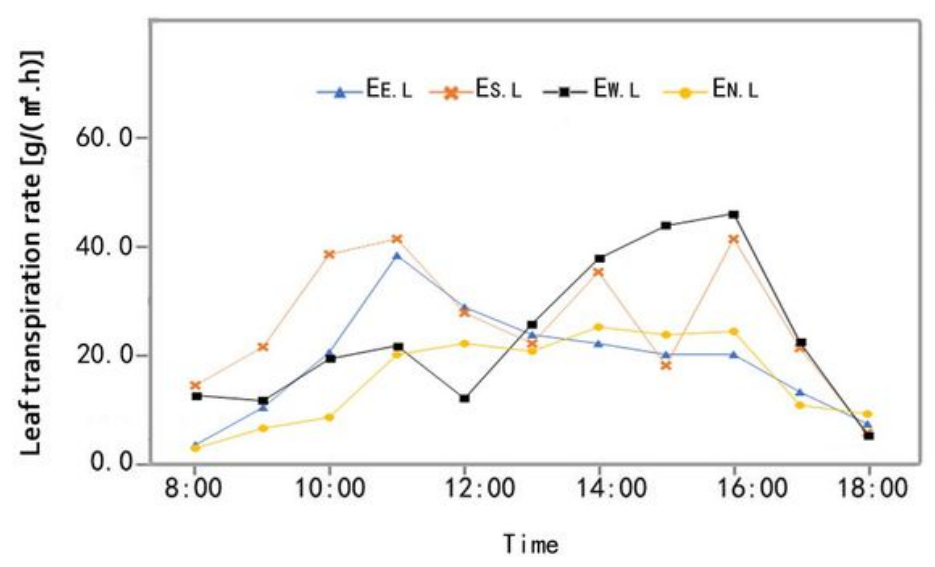

b: No. 4 Ficus altissima (Measuring point 4)

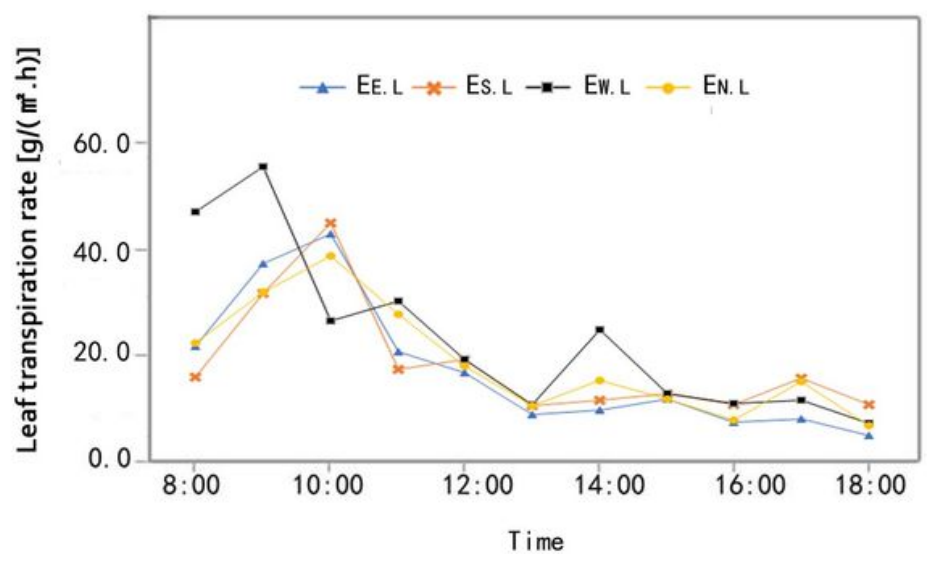

\section{Figure 4}

Transpiration rate of No. 3-4 Ficus altissima, the data was measured on January 14, 2021. EE.L, ES.L, EW.L, and EN.L represent leaf transpiration rate in the east, south, west, and north directions, respectively 

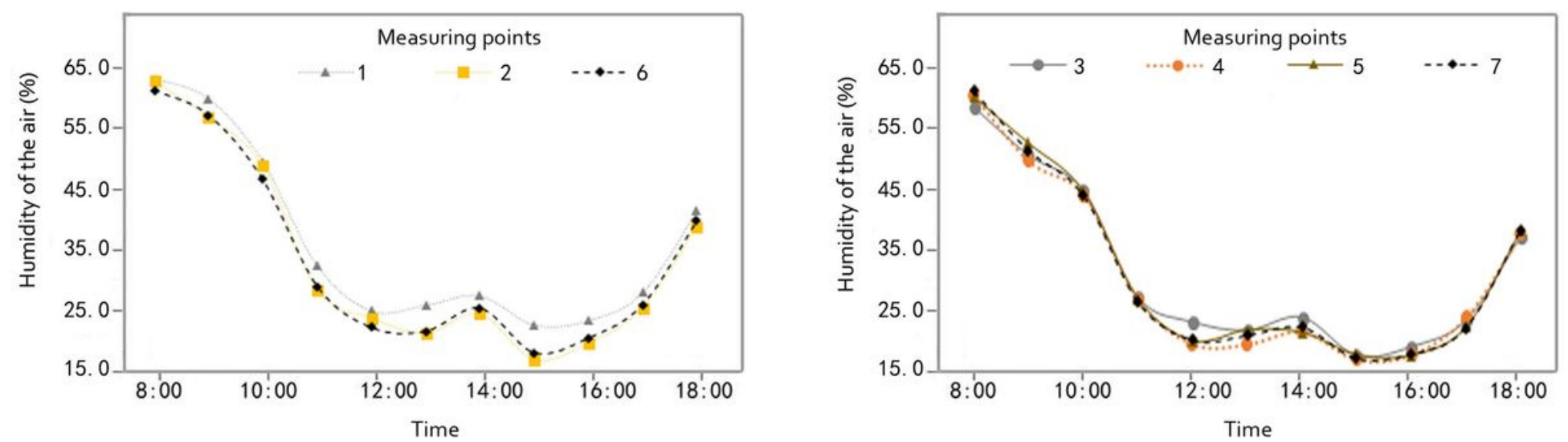

Figure 5

Changes of air humidity in groups A and B, the data was measured on January 13, 2021

a:Group A

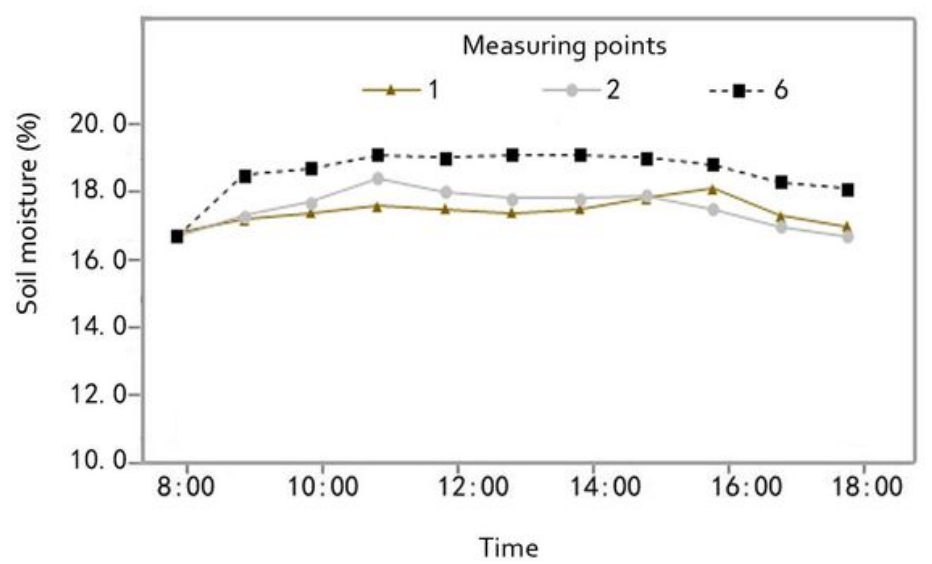

b:Group B

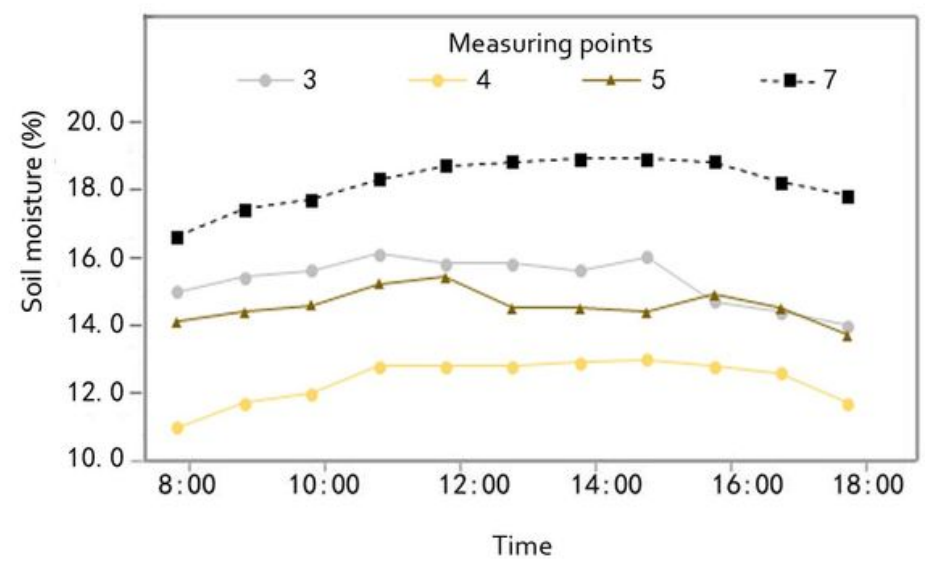

Figure 6

Changes of soil moisture in groups A and B, the data was measured on January 13, 2021 


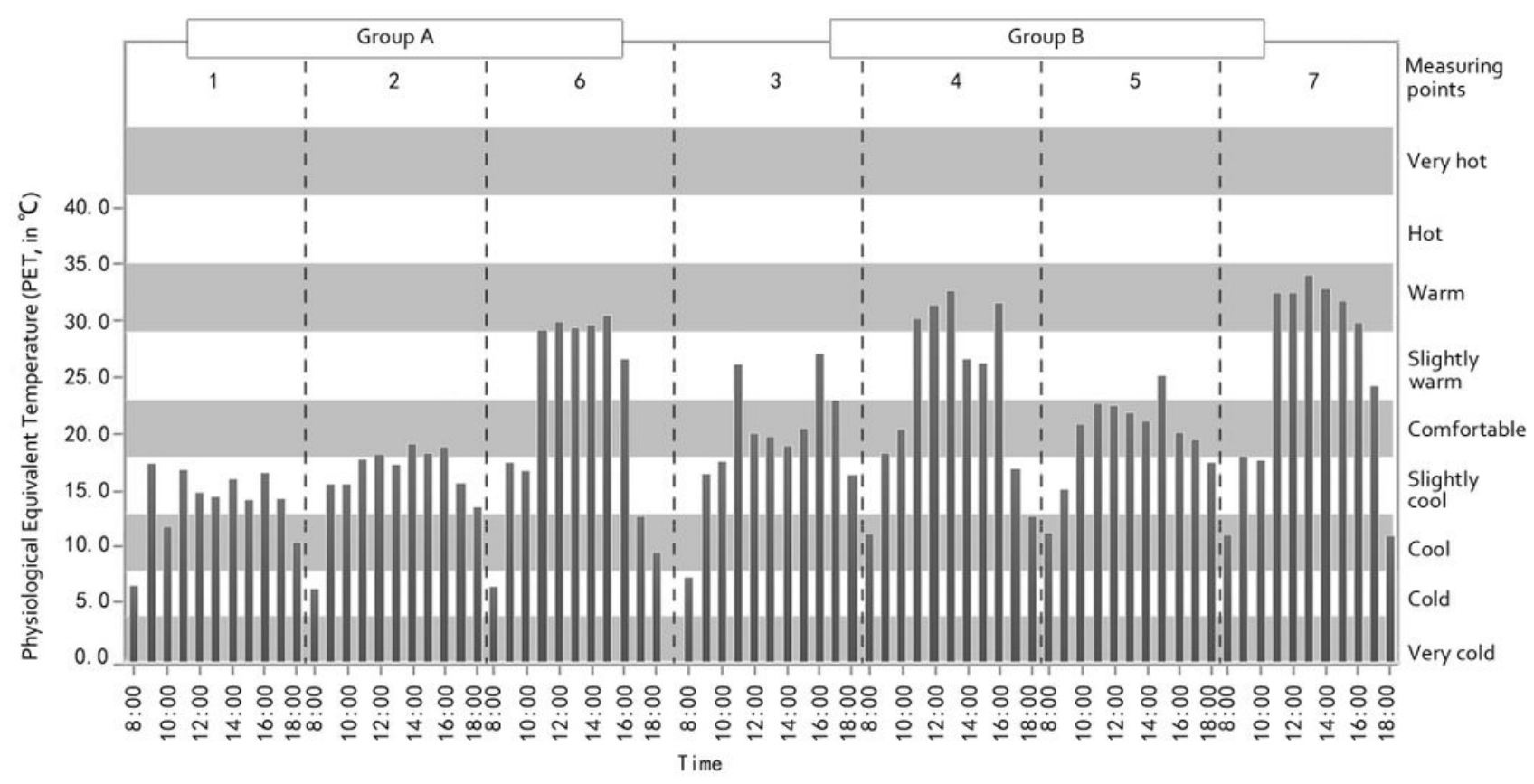

\section{Figure 7}

Thermal comfort analysis of measurement points 1-7. The vertical strip represents the hourly change of physiological equivalent temperature (PET) at measurement points $1-7$, while the horizontal strip denotes the defined interval of PET, seen in combination with Table 3 

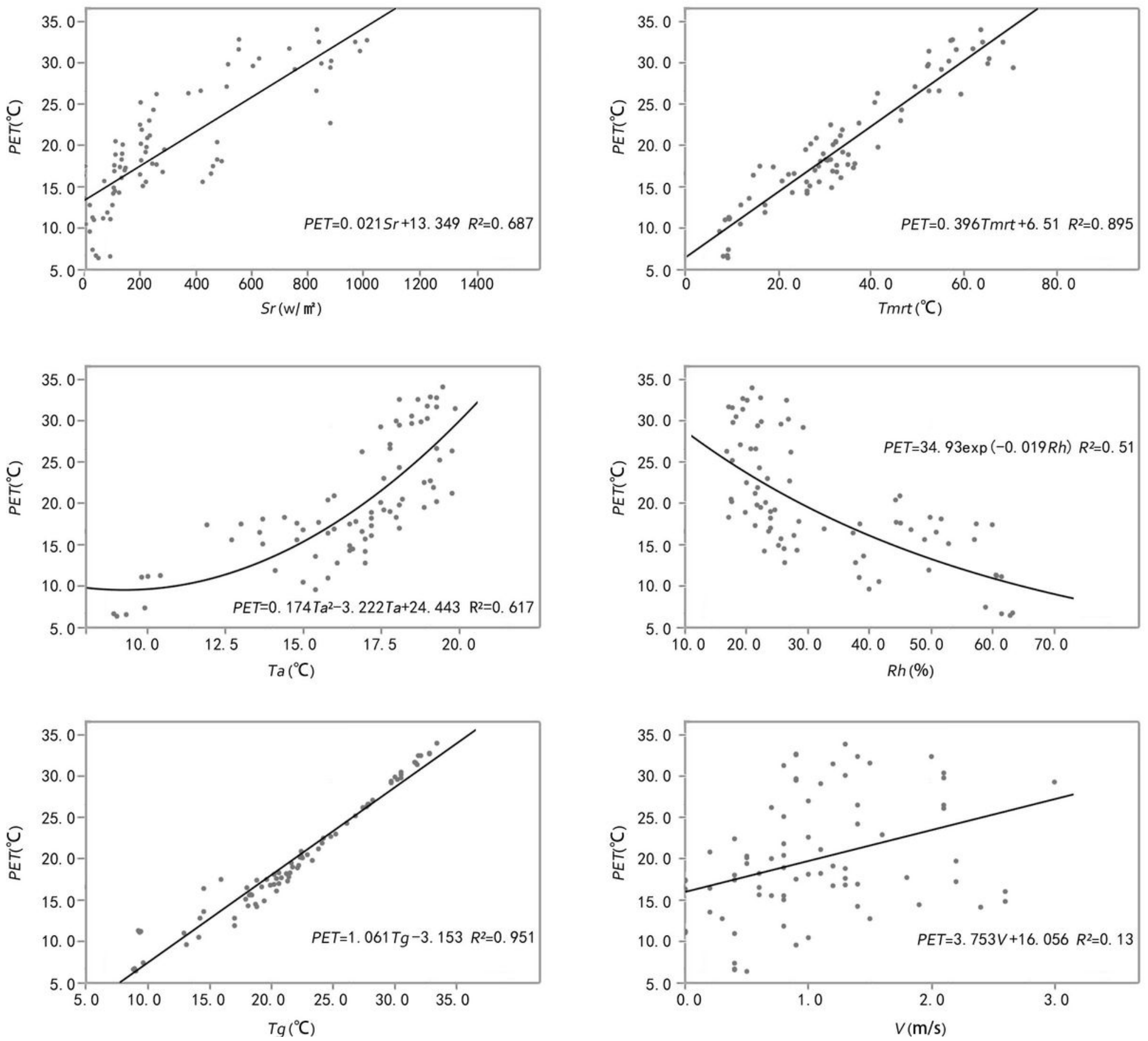

Figure 8

The functional relationship between PET and multiple climate factors. PET is the physiological equivalent temperature, $\mathrm{Sr}$ is the solar radiation, Tmrt is the Mean-radiant temperature, Ta is the air temperature, $\mathrm{Rh}$ is the air humidity, $\mathrm{Tg}$ is the globe temperature, and $v$ is the wind speed 